BHM (2015) Vol. 160 (2): 47

DOI 10.1007/s00501-015-0343-8

(C) Springer-Verlag Wien 2015

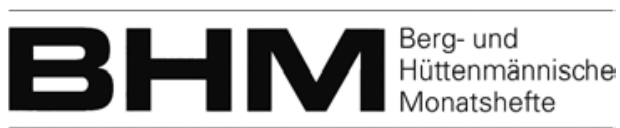

\section{Liebe Leser!}

Die Montanuniversität Leoben und mit ihr der BVÖ hatten bei der Herbstveranstaltung 2014 einen besonderen Anlass zu begehen. Vom 20. bis 21. November wurden beim Ehrenkolloquium "Bergbau - gestern - heute - morgen“ zwei führende und im höchsten Maße verdiente Persönlichkeiten des Bergbaus, der Montanuniversität und des BVÖ gefeiert.

Anlass dazu war der 90. Geburtstag von em. O. Univ.Prof. Dr.-Ing. Dr. h.c. mult. Günter B.L. FETTWEIS und der 75. Geburtstag von em. o. Univ.-Prof. Dipl.-Ing. Dr. mont. Horst WAGNER. Die beiden Emeriti des Lehrstuhls für Bergbaukunde, Bergtechnik und Bergwirtschaft haben zum BVÖ eine besonders enge Beziehung. Beide sind langjährig in der Leitung des Verbandes tätig gewesen. Dies nicht nur im Vorstand und Vorstandsausschuss, sondern besonders in der Funktion des Präsidenten. Beiden wurde für ihre herausragenden Leistungen und Verdienste, die sie sich um das Bergwesen erworben haben, die höchste Auszeichnung des Bergmännischen Verbandes Österreichs, die "Albert Miller von Hauenfels-Medaille", verliehen.

In diesem Umfeld wurde das Ehrenkolloquium derart gestaltet, dass die beiden Jubilare mit ihren Leistungen in ihrer aktiven Zeit, die noch lange wegweisend sein werden, dargestellt wurden. Darüber hinaus war es aber auch die Gelegenheit, einen Blick in die Zukunft zu wagen und markante Entwicklungen in unserem Fachbereich zu umreißen.
Dazu waren Wegbegleiter, Freunde und Schüler der Jubilare nach Leoben angereist und berichteten von ihren beruflichen, aber auch sehr persönlichen Verbindungen mit den Geehrten. Zweifelsfrei war der Beitrag von Altbundeskanzler Dr. Wolfgang Schüssel zum Thema "90 Jahre Europa, 1924 - 2014“ einer der Höhepunkte der Veranstaltung.

Als einer der Herausgebervertreter und Editor in Chief der BHM Berghefte ist es mir eine Freude, die Ausgaben 02/2015 und 04/2015 diesem Anlass zu widmen und die uns zugegangenen Beiträge der Tagung einer breiten Öffentlichkeit zugänglich zu machen.

\section{Glückauf!}

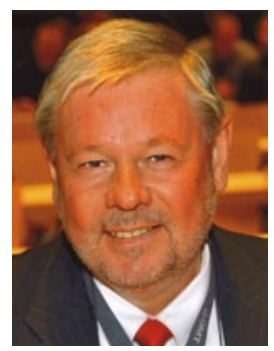

AssProf. Dipl.-Ing. Dr. mont. G. Mayer Montanuniversität Leoben, Lehrstuhl für Bergbaukunde, Bergtechnik u. Bergwirtschaft, Geschäftsführer des BVÖ Leoben, Österreich E-Mail: gerhard.mayer@unileoben. ac.at

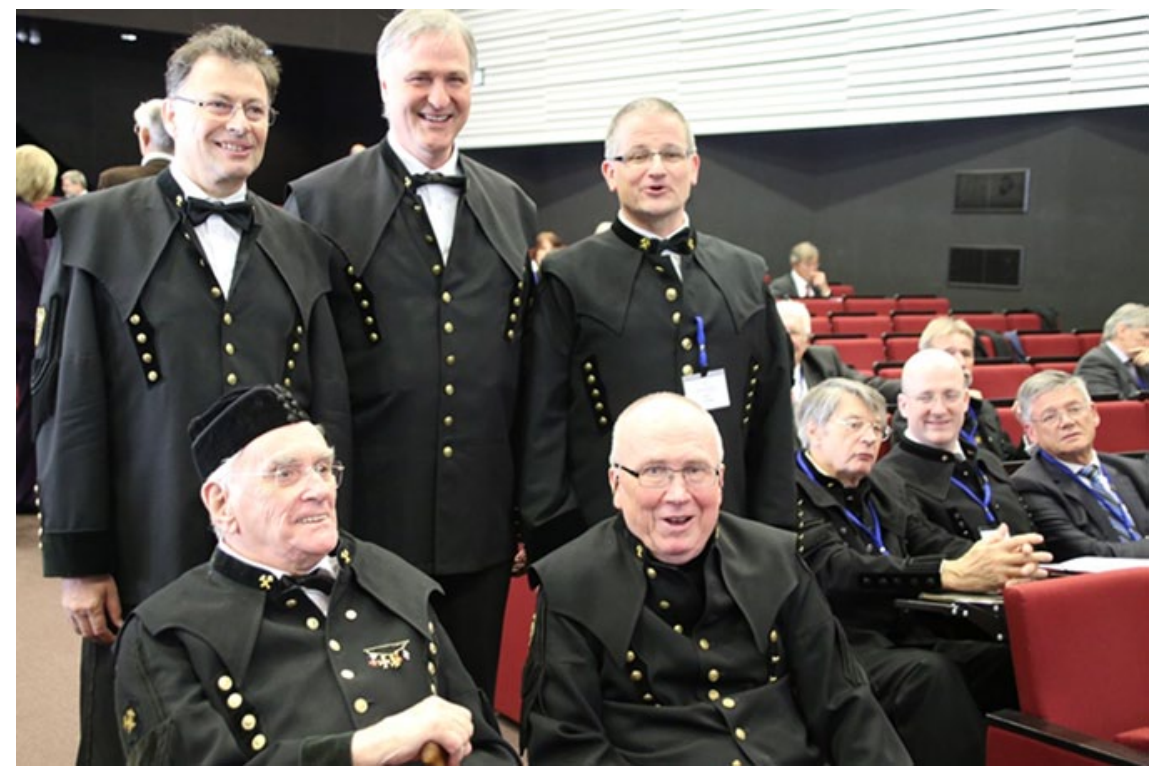

Stehend v.I.n.r. Rektor Eichlseder, Vizerektor Moser, BVÖ Präsident Martin Lang Sitzend v.l.n.r. die Emeriti Prof. Fettweis und Prof. Wagner 